\title{
ANÁLISE CRÍTICA DO NÍVEL DE CONHECIMENTO E DA UTILIZAÇÃO DE CONTROLE E GESTÃO PELOS PROPRIETÁRIOS RURAIS
}

\author{
CRITICAL ANALYSIS OF THE LEVEL OF KNOWLEDGE AND THE USE OF \\ CONTROL AND MANAGEMENT BY RURAL OWNERS
}

\section{Bárbara Dachery Patuzzi Correio \\ Bacharela em Ciencias Contábeis pela Universidade do Vale do Taquari - Univates (Lajeado/Brasil). \\ Alexandre André Feil \\ Doutor em Qualidade Ambiental pela Universidade Feevale (Novo Hamburgo/Brasil). Professor adjunto na Universidade Vale do Taquari - Univates (Lajeado/Brasil).}

\section{Angela Maria Haberkamp}

Doutoranda em Ciências Contábeis pela Universidade do Vale do Rio dos Sinos - UNISINOS (São Leopoldo/Brasil). Professora na Universidade Vale do Taquari - Univates (Lajeado/Brasil).

\section{Adriano José Azeredo Correio}

Mestre em Ciências Contábeis pela Universidade do Vale do Rio dos Sinos UNISINOS (São Leopoldo/Brasil). Professor na Universidade Vale do Taquari - Univates (Lajeado/Brasil). 


\section{RESUMO}

A administração de atividades rurais demanda conhecimento por parte dos produtores quanto à utilização de ferramentas que venham a qualificar a gestão e controle financeiro. Nesse sentido, este estudo objetiva analisar o nivel de conhecimento e a utilização das ferramentas contábeis no processo de gestão das propriedades rurais de dois municípios do Vale do Taquari - RS. A metodologia aplicada quanto à abordagem do problema é quantitativa, o procedimento técnico é survey por meio de questionário, a amostra não é probabilística e a coleta de dados ocorreu pela aplicação de 139 questionários. Os resultados revelam, em relação ao perfil sócio econômico, que há um baixo nivel de jovens e de escolaridade e um elevado grau de aposentados nas propriedades rurais. Já em relação à análise do nível de conhecimento e da utilização de ferramentas gerenciais nas propriedades rurais, a gestão é realizada pelo proprietário e família; possui um conhecimento parcial e total sobre meios de gestão e controle; separa os gastos do negócio dos particulares; tem noção do lucro, mas reinveste o mesmo quase por completo; a participação em treinamentos é em torno de $40 \%$; entendem que o controle financeiro é parcialmente satisfatório; e usariam a gestão contábil caso tivessem domínio da mesma. Conclui-se que o nível de conhecimento de ferramentas de controle e gestão, apesar de ser parcialmente satisfatório, não é utilizado na práxis, e um dos fatores que impede o processo, em especial, é a análise histórica cultural utilizada para controle e gestão.

Palavras-chave: Ferramentas contábeis. Gestão e controle financeiro. Atividade rural.

\section{ABSTRACT}

The administration of rural activities demands knowledge on the part of the producers regarding the use of tools that will qualify the management and financial control. In this sense, this study aims to analyze the level of knowledge and the use of accounting tools in the management process of the rural properties of two municipalities of Vale do Taquari - RS. The methodology applied to approach the problem is quantitative, the technical procedure is a questionnaire survey, the sample is not probabilistic and the data collection performed by the application of 139 questionnaires. The results reveal in relation to the socioeconomic profile that there is a low level of youth and schooling and a high degree of retirees in rural properties. In relation to the analysis of the level of knowledge and the use of managerial tools in the rural properties the management is carried out by the owner and family; Has a partial and total knowledge of the means of management and control; Separates business expenses from private individuals; Has notion of profit, but reinvests the same almost completely; Participation in training is around 40\%; They understand that financial control is partially satisfactory; And would use the accounting management if they had control of it. It concluded that the level of knowledge of control and management tools, although partially satisfactory, is not used in praxis and one of the factors hindering the process, in particular, is the cultural historical analysis used for control and management.

Keywords: Accounting tools. Financial management and control. Rural activity. 


\section{INTRODUÇÃO}

A atividade rural é historicamente reconhecida pela importância no desenvolvimento econômico e social, sendo mundialmente indispensável e estratégica devido às contribuições diretas e indiretas à alimentação da população, geração de renda, emprego, transferência de capital, matérias-primas à industrialização, exportações, diversidade biológica e equilïrio ecológico (DOĞAN; ARSLAN; KÖKSAL, 2013).

O desenvolvimento das propriedades rurais pode ser alcançado com o auxilio de ferramentas de gestão, por exemplo, os registros, contas, controles, entre outras, pois estes compreendem a condição essencial à eficaz gestão (UTEGl; UTEGI, 2014). Além disso, salientam que os agricultores, em nível global e de qualquer porte, devem ser encorajados a realizar, manter e analisar os registros contábeis das atividades na exploração agrícola (DOĞAN; ARSLAN; KÖKSAL, 2013). Estes controles caracterizam-se na ciência contábil como uma ciência da informação, tendo em vista que seu output (informação) busca impactar o julgamento, ou seja, a decisão.

A contabilidade é responsável por manter os gestores informados da situação de seu negócio, demonstrando sua real lucratividade e seus custos, mas no agronegócio é onde a contabilidade apresenta aderência e evolução mais tardia e, apesar da importância atrelada, ainda existe resistência (ULRICH, 2009). A contabilidade agrícola - rural - é uma especialidade que registra e controla as transações ao longo das atividades realizadas na propriedade rural, tais como as transações financeiras, gastos ocorridos durante o cultivo de produtos, receitas, entre outras (DOĞAN; ARSLAN; KÖKSAL, 2013).

A contabilidade rural mantém a propriedade rural eficiente por meio de seus procedimentos, outrossim, é uma questão vital a uma gestão eficaz das operações rurais que pode ser utilizada pelos gestores para tomar decisões em situações que afetam a rentabilidade (AL-SHARAFAT, 2016). Salientase, ainda, que sua ausência pode prejudicar a maximização da produtividade e/ou cultivo e a rentabilidade.

Os produtores rurais no Brasil carecem de consultorias e assessorias na área gerencial, desta forma, a atividade administrativa nas organizações rurais, principalmente na agricultura familiar, é frágil e insuficiente (LUCCA; SILVA, 2012). O produtor rural, devido a essa carência de subsídios gerenciais, pode ter prejuízos quanto à análise econômica dos resultados da produção em sua propriedade, além disso, sem perspectivas de investimentos e da produção de safras futuras (SHARMA, 2012). Neste contexto, este estudo objetiva analisar o nivel de conhecimento e utilização das ferramentas de controle e gestão das propriedades rurais em dois municípios da região do Vale do Taquari - RS.

A justificativa desta pesquisa vai ao encontro da percepção de que os processos gerenciais estão paulatinamente inseridos na rotina dos produtores rurais, implicando, assim, na busca de maior conhecimento sobre a gestão de seus negócios. Oliveira e Oliveira (2014) salientam que na atualidade o 
produtor rural recebe pressão de agentes informacionais sobre a operacionalização das atividades, em especial, em circunstancias decisórias. Consoante a isso, Oliveira, Rossoni e Feliciano (2010) expõem que a temática informacional tem permeado estudos no campo do agronegócio, principalmente abrangendo a relação entre subtemas como gestão da terra, informação e decisão. Dudafa (2013) salienta que é difícil imaginar que um país que busca a modernização agrícola não atribui a devida importância aos registos das transações - controles - como componente principal da modernização. Portanto, torna-se imperativo para todas as unidades agrícolas a adoção de ferramentas contábeis (SHARMA, 2012; TONEA, 2008).

\section{REFERENCIAL TEÓRICO}

\subsection{IDIOSSINCRASIAS DA ATIVIDADE RURAL}

A atividade agrícola pode ser definida como uma empresa rural que explora a capacidade produtiva do solo por meio do cultivo da terra, criação de animais e transformação de produtos agrícolas (MARION, 2010). A atividade agrícola apresenta a singularidade de ser interdependente, ou seja, diversos fatores podem interferir no decorrer do processo produtivo (GUILHOTO et al., 2006).

Os fatores intervenientes referentes ao setor agrícola e que interferem no processo econômico relacionam-se a: a) Dependência do clima: o clima condiciona as explorações agrícolas, determinando a época de plantio, tratos culturais, colheitas, escolha de variedades e espécies; b) Tempo de produção versus tempo de trabalho: o processo produtivo agropecuário desenvolve-se em algumas fases sem a necessidade de intervenção do trabalho físico, diferente de outros setores como a indústria, onde há a necessidade do trabalho para que haja produção; c) Dependência de condições biológicas: as condições biológicas determinam a impossibilidade de reversão do ciclo produtivo, não podendo, por exemplo, alterar a produção de um determinado grão para se obter outro, impede também que se utilizem medidas para acelerar a produção, como a implantação de mais turnos de trabalho; d) Incidência de riscos: como em qualquer atividade econômica, na atividade agropecuária, há maior possibilidade de riscos, pois esta pode ser afetada pelo clima, por ataques de pragas e moléstias e ainda pela flutuação dos preços dos produtos; e) Sistema de competição econômica: o produtor rural isoladamente não consegue controlar os preços de seus produtos, pois o setor possui algumas características como a existência de um grande número de produtores e consumidores, produtos que apresentam pouca diferenciação e a entrada ou saída no negócio pouco alteram a oferta total; e f) Produtos não uniformes: existe dificuldade de se obter produto uniforme em sua forma, tamanho e qualidade, pois depende das condições biológicas, acarretando custos adicionais com classificação e padronização, além do menor valor do produto em decorrência da qualidade inferior (CREPALDI, 2011). 
As características apresentadas por Crepaldi (2011) tornam o setor agrícola mais desafiador que os demais, quando se trata de contabilidade, pois configura-se diferente a forma de valorar seus produtos. Marion (2010) salienta que a receita da atividade agrícola se concentra durante ou logo após uma colheita, diferentemente de outras atividades cuja receita se distribui durante os 12 meses do ano. A comparação da atividade agrícola com outros ramos econômicos possui atividades especificas e que necessitam de atitudes adequadas diante da contabilidade (SEDLÁČEK et al., 2010).

\subsection{A CONTABILIDADE RURAL E A GESTÃO DE PROPRIEDADES RURAIS}

A contabilidade é uma ferramenta essencial na administração moderna e na gestão de negócios e auxilia nas tomadas de decisões (MELO; CUNHA; BAHIA, 2016; RODRIGUES et al., 2011). Neste sentido, é mister na gestão em propriedades rurais, pois o uso de informações contábeis pode melhorar o controle sobre as atividades desenvolvidas nas propriedades (TONEA, 2008). O controle por meio da administração objetiva o lucro, controlando os custos, produtividade e receitas (FLORES; RIES; ANTUNES, 2006). Além disso, verifica se a atividade está ou não alcançando os objetivos e metas estabelecidos, por ocasião do planejamento (SILVA et al., 2007).

As principais contribuições da contabilidade rural relacionam-se a (UTEGl; UTEGI, 2014; ALSHARAFAT, 2016): a) distribuição equitativa dos lucros; b) estimativa de ganho e perda; c) estimativa da carga fiscal, se existir; d) monitora e controla os recursos materiais e financeiros; e) auxilia na adoção de medidas preventivas no combate aos riscos; f) auxilia no planejamento do orçamento; g) fornece informações que facilita as transações operacionais e estratégicas; h) gera informações decisórias relacionadas com a agricultura, preços e rendas; i) determina e dá suporte à formação dos preços de produtos agrícolas; j) fornece informações válidas e confiáveis às instituições de crédito; e h) determina e apura os salários e pró-labores.

O controle e análise econômico-financeiro-patrimonial, em propriedades rurais, permite apurar os custos, atingir os objetivos de expansão que demandam capital, diversificar culturas, aumentar produtividade, realizar investimentos na estrutura da propriedade e registrar a evolução das contas a pagar e a receber (ZANIN et al., 2014; BORILLI et al., 2005). Esta formação de um sistema de informação é essencial nas práticas de tomadas de decisões e no direcionamento do futuro da propriedade rural (DOĞAN; ARSLAN; KÖKSAL, 2013). Entretanto, a gestão formal na agricultura familiar é escassa para a realização de decisões e utilização da tecnologia da informação (CLEMENTE et al., 2010).

As ferramentas gerenciais enfrentam dificuldades de ser implementadas em propriedades/ empresas rurais, em especial de base familiar, devido à transferência da administração de pai para filho, com práticas inapropriadas de gestão e a respectiva não profissionalização (COSTA et al., 2011). Os controles econômicos, segundo Crevelin e Scalco (2009), podem ser estabelecidos por meio de três 
métodos: 1. Estabelecimento de metas de produtividade e rentabilidade; 2. Planejamento de atividade na qual as principais práticas são a compra de insumos em época de preços baixos ou o deslocamento de custos de um período para o outro; e III. Escrituração de todas as despesas, custos e receitas oriundas da atividade.

O processo de gestão envolve uma visão global do empreendimento, aprendizado organizacional, liderança, inovação, busca por resultados e estabelecimento de parcerias, esses fatores podem culminar uma gestão integrada à propriedade e à sustentabilidade econômica da empresa rural (MARTINS, 2004). Uma empresa rural deve ser encarada como qualquer outra instituição, desta forma, as ferramentas contábeis auxiliam no processo de organização das informações para controle financeiro, gerando uma base sólida para dirigir uma propriedade da maneira mais adequada (MELO; CUNHA; BAHIA, 2016; AVILA; AVILA; FERREIRA, 2003).

As atividades rurais "[...] por menores que sejam, requerem um controle financeiro eficiente [...]", porém carecem de controles e organização financeira, sendo assim, na grande maioria não possuem "[...] condições para discernir os resultados obtidos com suas culturas, os custos de cada plantio desenvolvido em sua propriedade, verificar quais seriam os mais rentáveis, onde poderiam minimizar os custos de produção" (CREPALDI, 2011, p. 49).

As dificuldades quanto à gestão individual de propriedades podem ser relacionadas a: a) inadequação de ferramentas gerenciais voltadas a realidade da agricultura familiar; b) baixo nível de educação formal e específica dos agricultores e familiares; e c) falta de uma cultura que crie ambiente propício à adoção de práticas gerenciais (BATALHA; BUAINAIN; SOUZA FILHO, 2005).

\subsection{DIRETRIZES DA CONTABILIDADE RURAL}

A atividade rural segue princípios e orientações que norteiam a contabilidade rural, tais como: a) princípio da entidade contábil: o patrimônio é objeto da contabilidade, assim, deve-se diferenciar o patrimônio de sua empresa, no caso relativo à atividade rural, e o patrimônio particular do agricultor; b) princípio da realização da receita e da confrontação da despesa: confrontando as receitas e despesas que contribuíram para aquela receita, obtém-se o resultado; e c) princípio do custo histórico ou original como base de valor: os ativos são incorporados à entidade pelo valor original de aquisição ou pelo custo de fabricação mais todos os gastos necessários para colocar o ativo em condições a gerar benefícios para a empresa (MARION; SEGATTI, 2010).

O custo histórico ainda apresenta os seguintes aspectos, segundo Marion e Segatti (2010): a) Objetividade: é uma medida que não varia conforme quem está avaliando o ativo; b) Verificabilidade: qualquer valor do ativo poderá ser verificável, constando-se o mesmo valor; e c) Realização do lucro: 
somente lucro realizado é reconhecido. Estes princípios devem ser aplicados na escrita contábil em propriedades rurais, porém, a forma de escriturar a empresa/propriedade rural é de livre escolha e, no caso de sua utilização, esta deve ser um hábito permanente observando as normas da legislação vigentes (TONEA, 2008; CREPALDI, 2011).

Cabe enfatizar que além destas diretrizes sejam adotadas as normas internacionais de contabilidade -Internacional Financial Reporting Standards (IFRS) - e as leis n 11.638/07 e 11.941/07, declaradas pelo Comitê de Pronunciamentos Contábeis (CPC). A Norma Brasileira de Contabilidade (NBC) que norteia a contabilidade para empresas rurais relaciona-se à NBC T 10.14 - Entidades Diversas - Agropecuárias. Esta NBC apresenta os registros contábeis e demonstrações relacionadas à atividade rural, agrícola e pecuária. Portanto, essas diretrizes servem como base para o produtor proceder com registros contábeis de suas atividades, podendo ter maior controle e gestão de sua propriedade.

A disponibilização destas diretrizes voltadas à contabilidade rural, segundo Tonea (2008), acarreta oportunidades de mudar a situação de controle e gestão das propriedades rurais, entretanto, estas suportam principalmente contribuiç̧ões em nivel conceitual e que necessitam de ferramentas de aplicação prática.

\subsection{ESTUDOS PRECEDENTES SOBRE GESTÃO E CONTROLE NA ATIVIDADE RURAL}

A utilização da contabilidade rural e suas ferramentas de controle e gestão, com base em estudos anteriores (Quadro 1), aponta uma situação preocupante, pois os proprietários rurais não se utilizam de apoio para tomadas de decisões, sendo assim, são realizadas com base em historicidade, conhecimento popular e/ou experiências precedentes (CLEMENTE et al., 2010). 


\begin{tabular}{|c|c|}
\hline 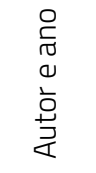 & Unidade de análise, objetivo e resultados \\
\hline 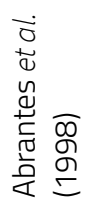 & $\begin{array}{l}\text { O escopo central foi tipificar e caracterizar os produtores rurais em relação ao uso de instrumentos } \\
\text { contábeis de controle. A pesquisa foi aplicada a } 360 \text { produtores rurais e revelou que não houve a utilização } \\
\text { de informações contábeis para tomadas de decisões; os produtores, em sua maioria, mantiveram os } \\
\text { registros na forma de anotações, e a contabilidade tinha como uso o atendimento à legislação fiscal e ao } \\
\text { crédito, entretanto, a minoria mantêm registros consistentes. }\end{array}$ \\
\hline 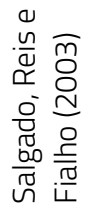 & $\begin{array}{l}\text { Objetivou avaliar técnica e gerencialmente a suinocultura no Vale do Piranga - Zona da Mata - de Minas } \\
\text { Gerais por meio de questionários. Os resultados revelam que em aspectos técnicos o sistema de produção } \\
\text { é confinado de alta tecnologia e eficiência. Entretanto, os produtores da região não adotam uma gestão } \\
\text { com técnicas racionais de controle de seus recursos, em especial dos recursos financeiros, sendo assim, } \\
\text { parte dos empresários baseia suas decisões apenas pelo senso comum. }\end{array}$ \\
\hline 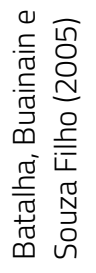 & $\begin{array}{l}\text { Buscou traçar a utilização das tecnologias de gestão pelos agricultores familiares brasileiros por meio } \\
\text { de uma pesquisa bibliográfica. Os resultados apontam que apesar das divergências culturais do Brasil } \\
\text { o proprietário rural centra-se na parte produtiva de sua atividade, causando uma carência na parte } \\
\text { administrativa, sendo assim, não utiliza ferramentas contábeis para auxílio na gestão. }\end{array}$ \\
\hline 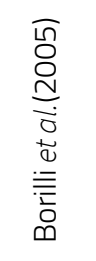 & $\begin{array}{l}\text { Este estudo demonstrou a importância da contabilidade rural para o pequeno, médio e grande produtor } \\
\text { rural, das ferramentas gerenciais, quanto à informação contábil, o planejamento e o controle orçamentário, } \\
\text { custos e comparação dos resultados. Sua realização ocorreu em } 21 \text { escritórios contábeis de Toledo-PR, } \\
\text { revelando que a utilização da Contabilidade Rural é escassa, e os que utilizam centram-se nas questões } \\
\text { tributárias. Além disso, demonstrou desconhecimento e o pouco interesse pela utilização das ferramentas } \\
\text { gerenciais. }\end{array}$ \\
\hline 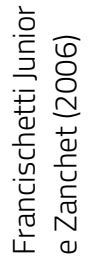 & $\begin{array}{l}\text { Analisaram o perfil contábil-administrativo de } 28 \text { produtores rurais de Marechal Cândido Rondon - PR, } \\
\text { para identificar o nível de utilização e implementação de modelos gerenciais para a tomada de decisão nas } \\
\text { propriedades por meio de uma pesquisa exploratório e survey. Os resultados revelam a quase inexistência } \\
\text { do nível de utilização de modelos gerenciais, sendo assim, suas decisões têm como base métodos } \\
\text { rudimentares de apontamentos e controles, com pouco ou nenhum conhecimento na área contábil- } \\
\text { administrativa. }\end{array}$ \\
\hline 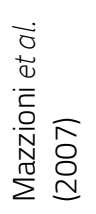 & $\begin{array}{l}\text { Verificaram a utilização da contabilidade como ferramenta de controle gerencial por meio de surveyaplicado } \\
\text { a } 100 \text { empresas rurais. Os resultados apontam que os proprietários separam as despesas particulares } \\
\text { de suas atividades agrícolas, porém não utilizam qualquer meio de anotação. O produtor não conhece o } \\
\text { custo de sua produção e o resultado obtido com clareza, sendo assim, possui dificuldades em conhecer e } \\
\text { reconhecer a contabilidade como meio de identificar, mensurar e analisar as informações de suas atividades. }\end{array}$ \\
\hline
\end{tabular}


(continuação)

\begin{tabular}{|c|c|}
\hline 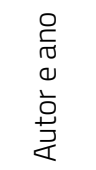 & Unidade de análise, objetivo e resultados \\
\hline 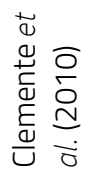 & $\begin{array}{l}\text { Examinaram os controles de custos de } 235 \text { propriedades rurais da região Centro-Sul do Paraná por meio } \\
\text { de uma pesquisa survey. Os resultados mostram que a agricultura familiar desta região é homogênea e os } \\
\text { controles de custos são precários. }\end{array}$ \\
\hline 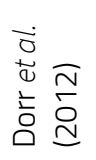 & $\begin{array}{l}\text { Analisaram a utilização de instrumentos de gestão contábil pelos produtores rurais em Santa Maria - RS. } \\
\text { Os resultados apontam que os produtores em sua maioria realizam a guarda de recibos e notas fiscais } \\
\text { como instrumento de controle das suas atividades. }\end{array}$ \\
\hline 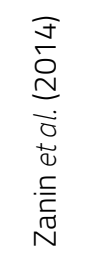 & $\begin{array}{l}\text { Identificaram as características da gestão das propriedades rurais do Oeste de Santa Catarina com a } \\
\text { utilização de pesquisa surveyem } 210 \text { proprietários rurais. A pesquisa revela que sua formação educacional } \\
\text { é ensino fundamental incompleto; a gestão é realizada em } 28 \% \text { por meio de controles e apenas } 10 \% \\
\text { utilizam o fluxo de caixa; apenas } 3 \% \text { dos filhos dos produtores têm interesse na sucessão familiar. Portanto, } \\
\text { o estudo demonstrou carência em frente à utilização de controles contábeis e fragilidades da estrutura } \\
\text { organizacional e de planejamento. }\end{array}$ \\
\hline 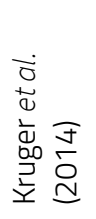 & $\begin{array}{l}\text { Identificaram o uso da contabilidade como instrumento de gestão de } 150 \text { propriedades rurais de Erval } \\
\text { Grande - RS, por meio de survey. Os resultados apontam que não há uma separação de seus gastos } \\
\text { particulares dos gastos com as atividades rurais; } 48 \% \text { desconhece a finalidade da contabilidade, sendo } \\
\text { assim, há uma carência dos gestores rurais quanto à utilização da contabilidade como ferramenta de apoio } \\
\text { às decisões. }\end{array}$ \\
\hline 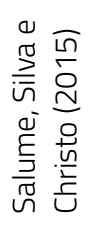 & $\begin{array}{l}\text { Avaliaram a aplicação das premissas básicas e funções da gestão em } 12 \text { propriedades rurais de Alegre - ES, } \\
\text { por meio de pesquisa survey. Este estudo revelou que os proprietários não utilizam-se de controles para } \\
\text { tomada de decisões. }\end{array}$ \\
\hline 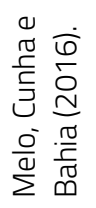 & $\begin{array}{l}\text { Verificaram quais ferramentas de gestão pequenos e médios produtores rurais do Triângulo Mineiro-MG } \\
\text { utilizam de apoio às decisões. Os resultados suportam que há um desconhecimento generalizado em } \\
\text { relação às ferramentas contábeis, sendo utilizada meramente para fins tributários. }\end{array}$ \\
\hline
\end{tabular}

\section{Fonte: Elaborado pelos autores}


A contabilidade rural no Brasil, além da carência apontada em relação aos produtores rurais, também é apontada nos profissionais contábeis (BASTOS, 2011). Esta questão também pode ser vista em estudo realizado na Grécia, onde Vazakidis, Stergios e Laskaridou (2010) apontam que os profissionais contábeis não atribuem a importância necessária à contabilidade rural por meio de pesquisas e práxis; e na Nigéria, Dudafa (2013) revela que a maioria dos produtores não mantém registros das transações.A comparação desta informação com pesquisas brasileiras também aponta que as ferramentas contábeis são utilizadas para questões tributárias e não como ferramentas de controle e gestão, e sua utilização não é legalmente obrigatória (MELO; CUNHA; BAHIA, 2016; BORILLI et al., 2005; ABRANTES et al., 1998).

\section{METODOLOGIA}

\subsection{TIPO DE PESQUISA}

O tipo de pesquisa empregada quanto à abordagem é quantitativa, pois caracteriza a quantificação da coleta de informações, bem como o tratamento estatístico dessas coletas (RICHARDSON, 1985). Neste estudo, aplica-se um questionário fechado e com base nestas informações analisa-se, com o auxílio de percentagens médias, os resultados para satisfazer o escopo central da pesquisa.

O procedimento técnico empregado compreende a pesquisa survey, a qual parte da aplicação de interrogações diretas a determinado grupo de pessoas que se deseja estudar, e além disso, recomendada em análises quantitativas (GIL, 2010). Esta classificação adere-se em função da coleta de informações serem oriundas diretamente de produtores e/ou gestores rurais, questionando os respondentes sobre 0 uso e conhecimento sobre gestão e controle. A surveyfoi viabilizada pela utilização de questionário fechado, e este compreende um conjunto de perguntas ordenadas a respeito de determinado tema (SILVA, 2003).

A pesquisa, quanto aos fins, detalha-se como descritiva, pois seu objetivo principal é a descrição das características de determinada população, e sua especificidade mais expressiva adere-se na utilização de técnicas padronizadas de coleta de dados (MARCONI; LAKATOS, 2010; GIL, 2010). Logo, esta pesquisa é descritiva, pois ocorreu pelo registro, análise e interpretação de dados, sem interferência do pesquisador, apresentando as principais caracterizações do perfil sócio-econômico-financeiro, nível de uso e de conhecimento sobre ferramentas de gestão e controle na área rural. 


\subsection{POPULAÇÃO E UNIDADE DE ANÁLISE}

A população é um conjunto de indivíduos cujas características serão objeto de estudo (VERGARA, 2007). Já a amostra é o subconjunto do universo, uma parcela da população escolhida para realização da pesquisa (SILVA, 2003), além disso, Mattar(1996) salienta quea amostragem não probabilística se relaciona à seleção dos elementos para compor a amostra e depende do julgamento do pesquisador. A unidade de análise desta pesquisa compreende os produtores rurais administrador-gestor de dois municípios que integram a região do vale do Taquari-RS. O nome dos municípios será mantido em sigilo, em função das informações financeiras e pessoais coletadas pela survey, sendo assim, denominados de Região A e Região B. Estas regiões atuam, em especial, nas atividades de agropecuária, indústria e de serviços, sendo assim, o setor agropecuário é responsável por 69,55\% do Produto Interno Bruto (PIB) na região A e 51,32\% do PIB na região $B$ (IBGE, 2014). Esta informação foi utilizada como limiar na escolha destas regiões para compor a população da pesquisa. A unidade de análise foi composta por 70 respondentes na Região A e 69 respondentes na Região B, sendo o total de 139 respondentes proprietários-gestores rurais.

A amostragem utilizada neste estudo não é probabilística, sendo assim, por conveniência. Esta escolha fundamenta-se em função das regiões A e B pertencerem à atividade rural e os produtores localizarem-se em uma área geográfica dispersa, e a aplicação do questionário necessita ser entregue e recolhida pessoalmente pelos pesquisadores, pois não possuem serviços de entrega de correio eletrônico e/ou físico.

\subsection{COLETA, TRATAMENTO E ANÁLISE DE DADOS}

A coleta das informações realizou-se por meio da aplicação de questionário fechado com múltiplas escolhas (ANEXO A). Este questionário foi adaptado de Kruger et al. (2014) e Salume, Silva e Christo (2015), pois estes estudos já realizaram a validação do questionário e assim não houve a necessidade de realização de pré-teste, além disso, o questionário abrange todas as informações necessárias na solução do escopo central deste estudo. Cabe salientar que este estudo se diferencia dos anteriores pela profundidade das análises em torno dos resultados. O questionário foi entregue e recolhido aos proprietários-gestores das regiões $A$ e $B$, onde em cada propriedade apenas um respondente preenchesse o questionário, independentemente da quantidade de familiares; isto ocorreu entre o dia 5 e 30 de setembro de 2016. A entrega total de questionários foi de 160, sendo que, destes, 15 não foram devolvidos e seis estavam incompletos ou rasurados, o que totalizou 139 questionários válidos.

Os questionários foram recolhidos e tabulados com o auxílio do Software Microsoft Office Excel , neste, nas linhas, foram inseridos os respondentes e nas colunas as respostas à cada uma das questões. 
Esta tabulação facilita a geração de gráficos e comparativos na seção dos resultados e análises dos dados. A análise das informações ocorreu pela análise interpretativa com auxílio de gráficos de pizza e barras.

\subsection{LIMITAÇÕES DO MÉTODO}

O método apresenta possibilidades e limitações, diante disto, é conveniente o pesquisador adiantar-se às críticas, deixando claras as limitações (VERGARA, 2007). Os resultados desta pesquisa não podem ser utilizados para descrever o comportamento da população da região $A$ e $B$, mas apenas da amostra selecionada, pois a amostra é não probabilística. Salienta-se que os respondentes podem não ter respondido o questionário com base na realidade da propriedade, pois o fator de confiança pode ter interferido na disponibilização de informações consideradas sensíveis.

\section{RESULTADOS}

\subsection{ANÁLISE DO PERFIL SOCIOECONÔMICO}

A análise da idade (Q1) revela que 84,1\% estão em idade economicamente ativa (Gráfico 1), porém a taxa de renovação é preocupante, pois somente 0,7\% possuem até 20 anos. 0 nível de escolaridade (Q2A) demonstra uma predominância do ensino fundamental incompleto e no ensino médio completo, além disso, 7,9\% possui ensino superior completo ou incompleto. 


\section{Gráfico 1 - Idade, escolaridade e renda}

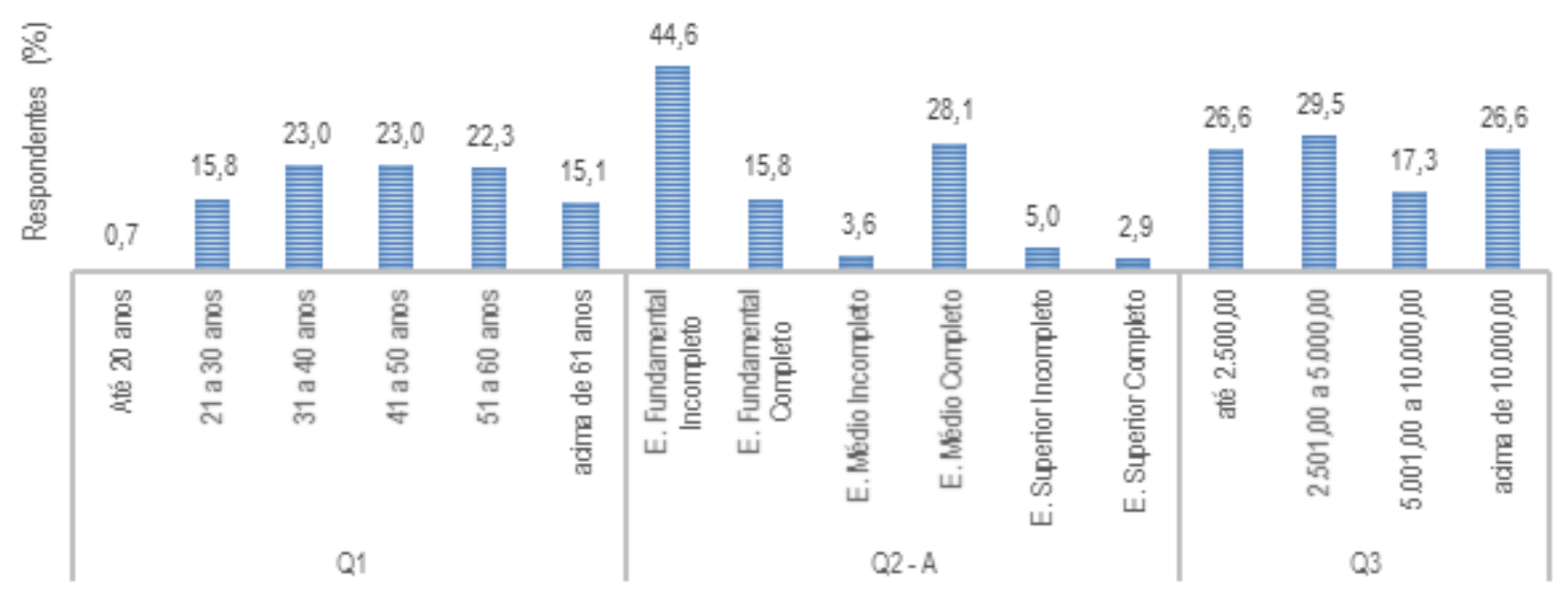

Fonte: Elaborado pelos autores

Os respondentes revelam que a quantidade de hectares totais por propriedade centra-se entre 17,7 e 48,2 hectares, representando 92\% (Gráfico 2); já a quantidade de hectares cultivados centra-se entre 10,9 e 28,7 hectares, o que representa $87,7 \%$. Os dados demonstram também uma taxa de ocupação média de $60 \%$, o que pode ser explicado em função das áreas de proteção permanentes que são frequentes nestas propriedades rurais.

\section{Gráfico 2 -Frequência de hectares por propriedade}
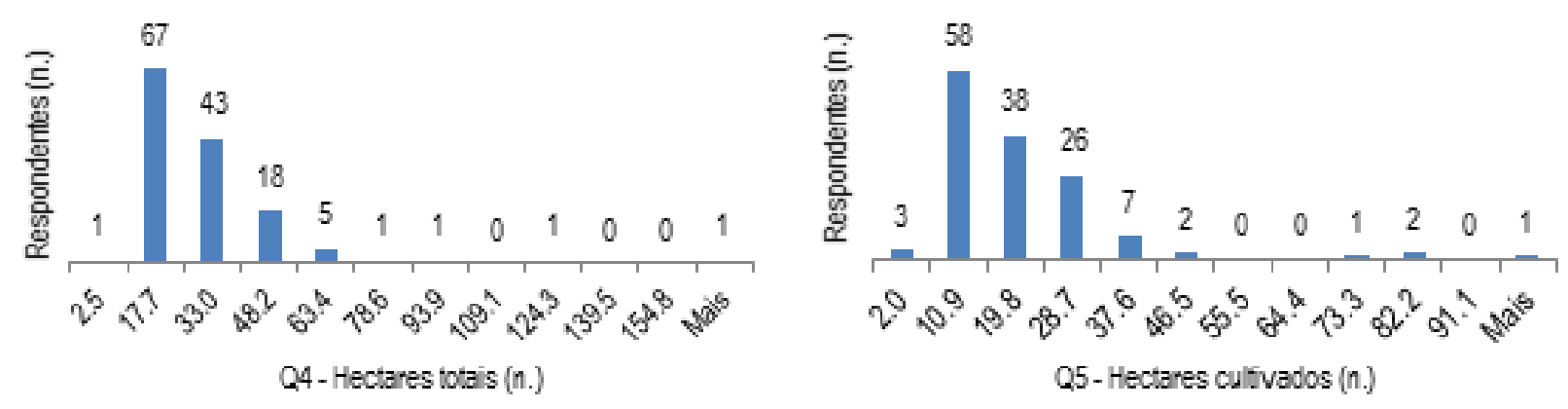

Fonte: Elaborado pelos autores 


\section{Gestãoe \\ Desenvolvimento}

A análise da atividade predominante (Q6) relaciona-se com o cultivo de milho, soja e bovinos de leite (Gráfico 3).

\section{Gráfico 3 - Tipo de atividade nas propriedades}

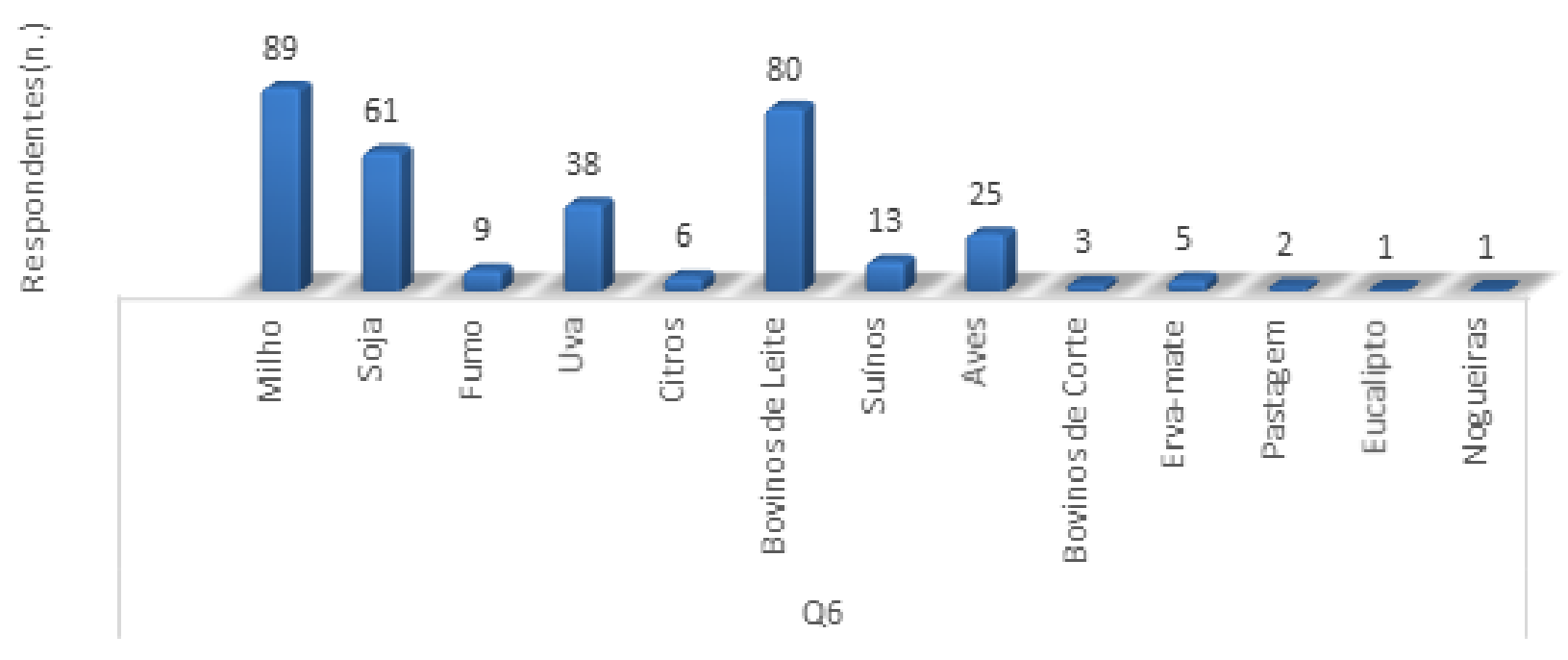

\section{Fonte: Elaborado pelos autores}

A Q7-A (Gráfico 4) demonstra que em 70,5\% das propriedades rurais residem aposentados. Na Q8-A se verifica que $82,7 \%$ dos respondentes não desenvolve cargos de gestão na comunidade. Os $17,3 \%$ que 0 fazem assumem papéis como de presidente, tesoureiro, fiscal, conselheiro e secretário (Q8-B). 
Gráfico 4 - Atividade exercida, cargo comunitário, mão de obra e número de filhos

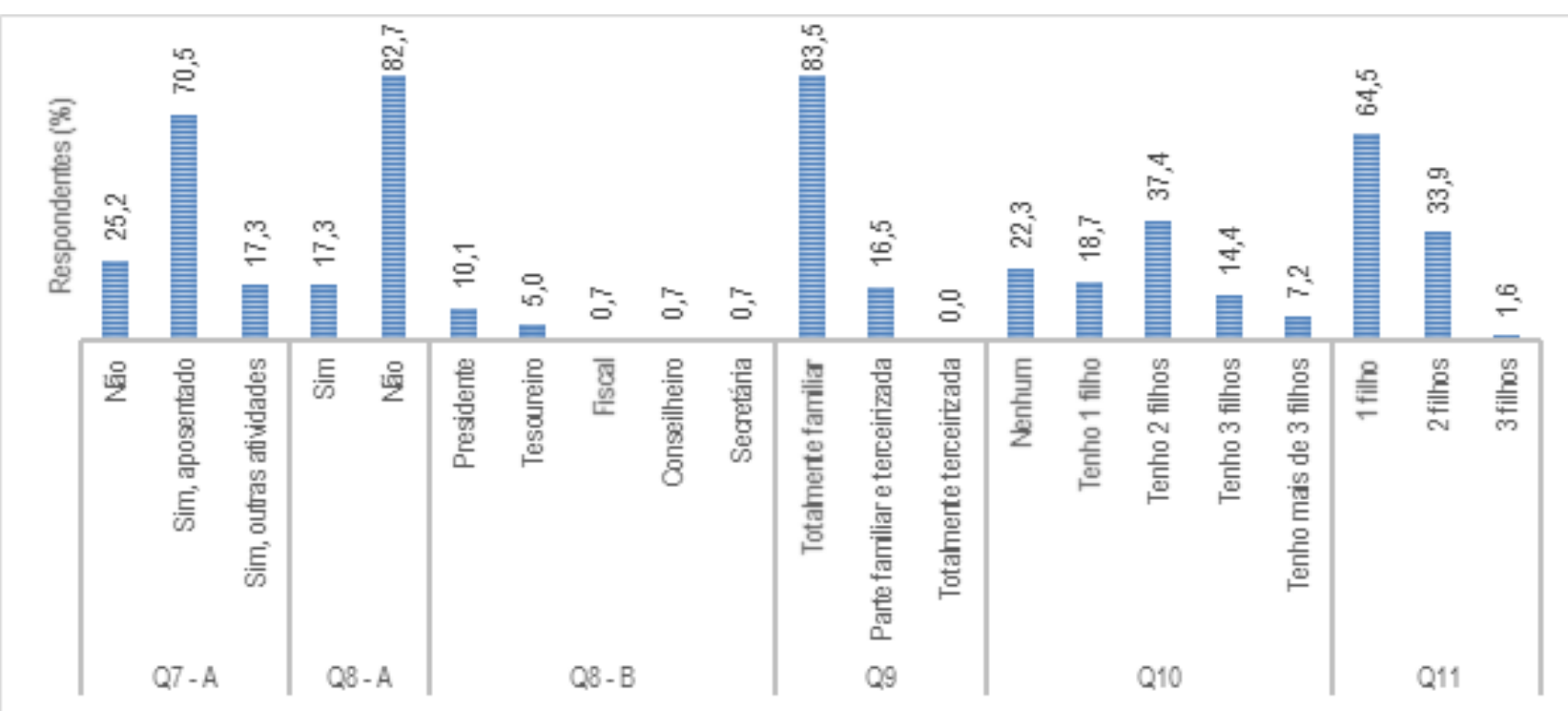

Fonte: Elaborado pelos autores

Verifica-se, na Q9, que a mão de obra aplicada nas propriedades rurais é, em suma, familiar (Q9). Poucas são as propriedades rurais que terceirizam a mão de obra (16,5\%), apenas as que possuem grandes plantações em época de plantio e de colheita. Na Q10, os respondentes revelam que o número de filhos entre 1 e 3 é de $70,8 \%$, e destes, a Q11 revela que $64,5 \%$ dos respondentes informaram que apenas um filho atua na propriedade rural.

\subsection{ANÁLISE DO CONHECIMENTO E UTILIZAÇÃO DE FERRAMENTAS CONTÁBEIS}

A administração-gestão das propriedades rurais (Q12) é realizada pelos integrantes familiares em $98,6 \%$ (Gráfico 5), e os 1,4\% representam duas propriedades às quais são cultivadas pelos arrendatários, e quem auxilia na gestão são os proprietários legais da área. 
Gráfico 5 - Características do controle e gestão da propriedade rural

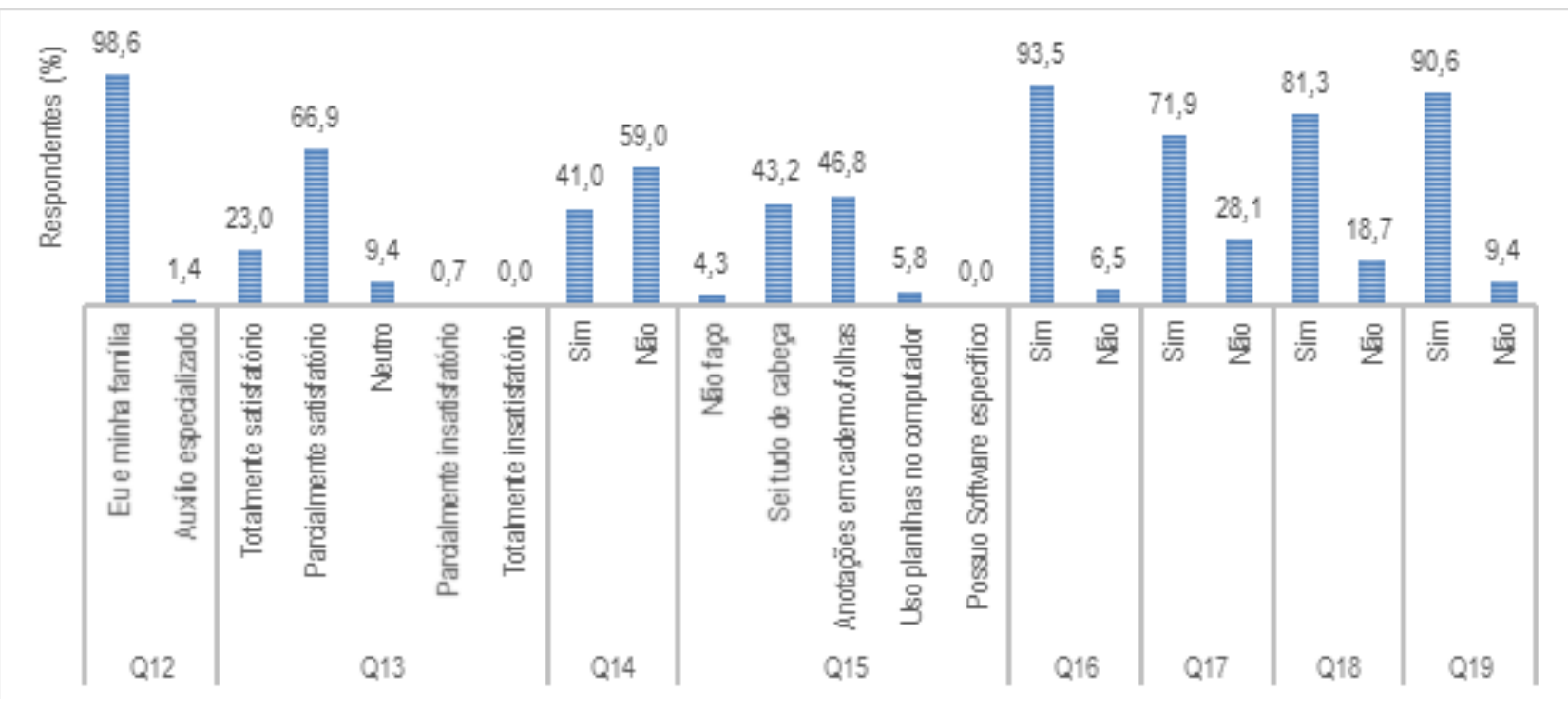

Fonte: Elaborado pelos autores

Os respondentes, em sua maioria, entendem que seu nivel de conhecimento é parcialmente satisfatório (66,9\%), e 23\% acreditam que é totalmente satisfatório (Q13). Quanto à análise da Q14, verificase que $41 \%$ dos respondentes realiza a separação dos gastos pessoais daqueles da produção rural. Os respondentes que realizam essa separação possuem controle na propriedade através de anotações em cadernos ou planilhas e sem nenhuma anotação (Q15).

A análise da Q16 revela que 93,5\% tem conhecimento do lucro gerado pela propriedade, e a Q19, que trata sobre o reinvestimento do lucro na propriedade, gira em torno de $90,6 \%$, além disso, o controle das perdas (Q17) e o planejamento em função do lucro são realizados em 71,9 e 81,3\% das propriedades. A Q20-A revela que 48,2\% dos respondentes já participaram de treinamento sobre gestão, controle e administração de propriedade rural, e este foi proporcionado em especial pela Emater (Q20-B - Gráfico 6). 


\section{Gráfico 6 - Características do controle e gestão da propriedade rural}

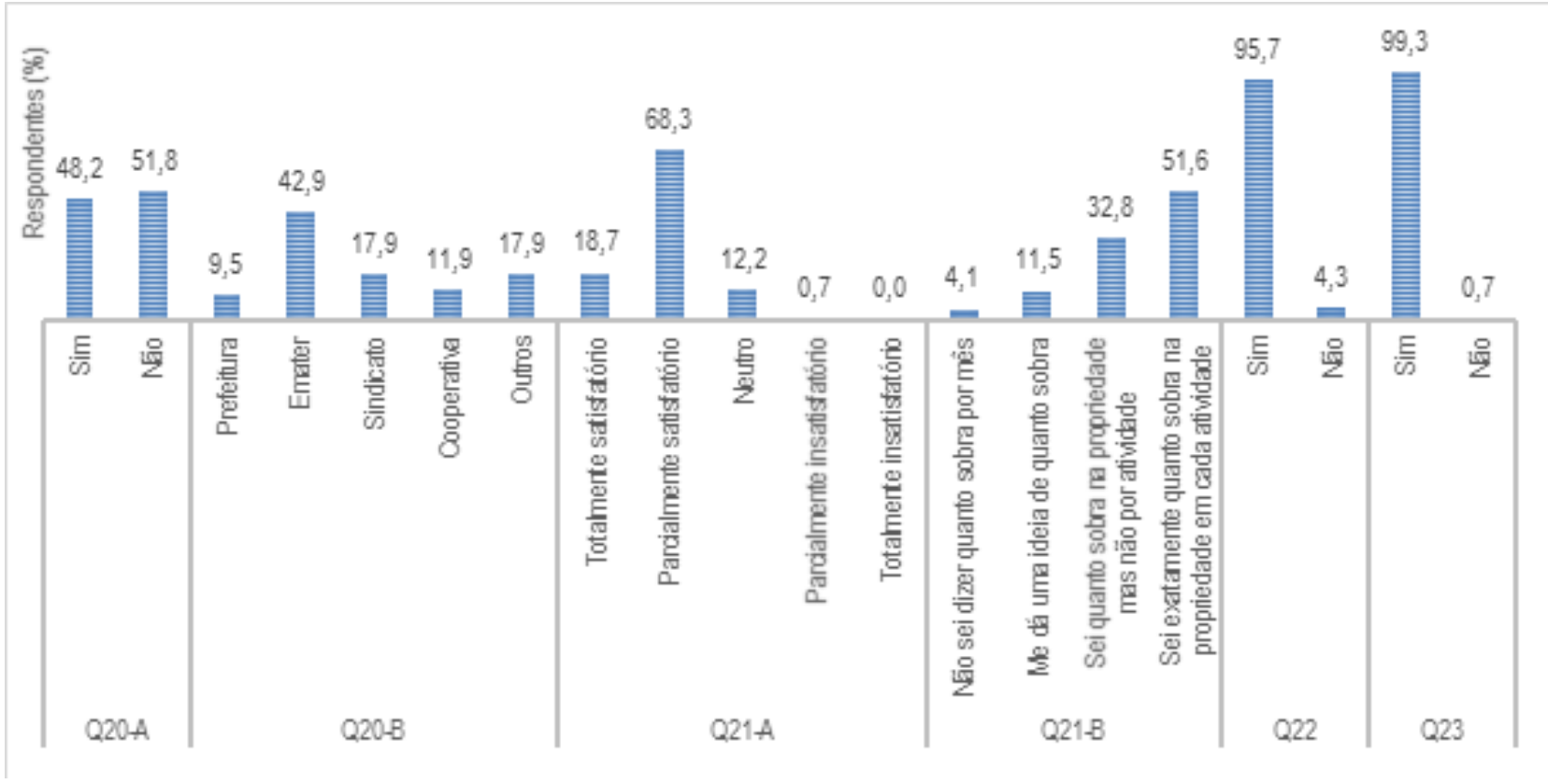

\section{Fonte: Elaborado pelos autores}

Os respondentes consideram que o controle financeiro de sua propriedade rural é parcialmente satisfatório (Q21-A - 68,3\%) e entendem que sabem com exatidão o ganho por atividade em 51,6\% (Q21-B). Os respondentes revelam, em 95,7\% dos casos, que a contabilidade pode auxiliar no controle do fluxo financeiro, despesas e lucros (Q22), e 99,3\% dos respondentes usariam caso tivessem domínio desta ferramenta (Q23). Deve-se considerar que, dado o nivel de escolaridade dos respondentes, estes desconhecem conceitos de depreciação, pró-labore e custo de oportunidade, considerando como ganhos a sobra de caixa.

\subsection{DISCUSSÕES DOS RESULTADOS}

A análise do perfil socioeconômico revela, em especial, que há poucos jovens, um baixo nível de escolaridade e um elevado grau de aposentados nas propriedades rurais. 0 envelhecimento da população rural tem como consequência a redução dos jovens, o retorno dos aposentados do ambiente urbano ao campo, aumento da expectativa de vida e redução do grau de fecundidade (ANJOS; CALDAS, 2005). 
Nota-se que no meio rural tem-se estabelecido, em especial, pessoas idosas, e os jovens demonstram pouco interesse para continuar a atividade - desinteresse na sucessão familiar. Estes preferem residir e empregar-se no meio urbano, esta situação é considerada um paradoxo inexplicável, pois os jovens, como donos de um negócio na atividade rural, migram para os centros urbanos para serem empregados.

Os principais paradoxos relacionam-se à dependência climática para o sucesso da produção, à situação de preços dos produtos agro, elevado gasto de produção pela tecnologia empregada para garantir a produtividade, penosidade do trabalho e à imagem negativa da atividade, sendo estes aderentes ao RuralNews (2015) e Mendonça, Ribeiro e Galizoni (2008). A escolaridade e o nível de instrução dos proprietários rurais, apesar da intensificação tecnológica e modernização, ainda são reconhecidos como desqualificados e escassos, este entendimento também pode ser visto em Anjos et al. (2006).

A análise do nível de conhecimento e da utilização de ferramentas gerenciais nas propriedades rurais revela, em especial, que a gestão é realizada pelos proprietários e famílias; e estes possuem um conhecimento parcial e total sobre meios de gestão e controle; separam os gastos do negócio dos particulares; têm noção do lucro, mas reinvestem o mesmo na integralidade; a participação em treinamentos é em torno de 40\%; entendem que o controle financeiro é parcialmente satisfatório; e usariam a gestão contábil caso tivessem domínio da mesma.

Nestes resultados, notam-se incoerências, pois os proprietários afirmam que possuem um conhecimento parcial e satisfatório sobre controle e gestão, mas também apontam que usariam a gestão se tivessem domínio, mas também não têm interesse, analisando-se a participação em treinamentos. Além disso, também revelam que realizam a separação de gastos pessoais e produtivos, em $41 \%$ das respostas, mas quando se trata em conhecer o lucro gerado, este percentual se eleva a 93,5\%. Estas incoerências podem ser consideradas indícios de que o controle e gestão realizados pelos proprietários rurais difere daquele dos conceitos revistos pela literatura e/ou a existência de má aplicabilidade das ferramentas, sendo assim, podem não ter respondido com a devida eloquência.

O reinvestimento do lucro gerado pela propriedade revela que o proprietário não possui controle e gestão condizente com sua avaliação, pois não há planejamento de suas finanças e nem das finanças da propriedade. Ademais, salienta-se que a transferência da propriedade de geração em geração não ocorre apenas do capital imobilizado, mas de um elevado fator denominado de código cultural, o qual reflete um impacto sobre o controle e a gestão de forma complexa. Esta questão pode explicar a limitada utilização e pouco conhecimento do controle e da gestão no meio rural, pois ainda há um vasto nível de conhecimento popular empregado na administração cotidiana, e o conhecimento científico é desprezado por não acreditar nas ferramentas oportunas, por exemplo, contábeis, ou pelo próprio desconhecimento de sua existência e aplicabilidade. Portanto, o produtor rural não prioriza a gestão e controle, mas as atividades operacionais, 
além disso, utiliza-se de tradições históricas produtivas para a realização da gestão e não na conjuntura atual, o que corrobora os estudos de Breitenbach (2014) e Tonea (2008).

\section{CONCLUSÃO}

A produção rural representa o setor primário da economia e atende o mercado interno e externo, com alimentos e matéria-prima. Nesse sentido, o objetivo central deste estudo buscou analisar o nível de conhecimento e a utilização das ferramentas contábeis no processo de gestão das propriedades rurais.

Os resultados apontam que os produtores rurais, apesar de responderem que o nivel de conhecimento é parcial $(66,9 \%)$ e totalmente $(23,0 \%)$ satisfatório em sua maioria, apresentam incoerência quando esta é comparada com outras questões, tais como: o lucro gerado; e que se tivessem domínio das ferramentas usariam, - esta questão deixa claro que não utilizam as ferramentas e que ter o apropriado conhecimento difere da ideia de utilizá-lo no cotidiano. Outra situação que sustenta esta conclusão é o reinvestimento do lucro na propriedade, o qual é realizado quase na sua totalidade, o que pode gerar descapitalização e até a falência financeira da propriedade, pois em função das características específicas das propriedades rurais é fortemente recomendado que haja uma reserva financeira para utilizar em momentos de crise, em função de impactos mercadológicos ou ambientais.

Um dos fatores que interferem no processo de utilização de ferramentas contábeis no controle e gestão é ser uma propriedade familiar, onde a propriedade é transferida para a próxima geração e com o capital físico é transmitida a forma histórica - cultura - de gestão e controles. Geralmente, após a transferência da propriedade, o antigo proprietário ainda auxilia no processo de gestão e no controle da propriedade, por meio de seu conhecimento popular adquirido ao longo de suas atividades.

Os resultados deste estudo demonstram a importância de conscientização dos proprietários rurais de que o processo de produção rural, na atualidade, é similar ao processo industrial e que exige adequados controles de gastos e receitas para atingir determinado resultado. Sugere-se que os órgãos estaduais, por exemplo, EMATER, SENAR em conjunto com as secretarias da agricultura municipal incentivem e auxiliem estes proprietários para a utilização cotidiana de controles, por meio de assistências efetivas e consistentes. 


\section{REFERÊNCIAS}

ABRANTES, L. A. et al. Tipificação e Caracterização dos Produtores Rurais Através da Utilização de Informações Contábeis. Organizações Rurais e Agroindustriais. Lavras, MG, v. 10, n. 2, p. 22-34, jun./dez. 1998.

AL-SHARAFAT, Ali. The Impact of the Use of Agricultural Accounting on the Financial Performance of Broiler Industry: A Comparative Evaluation Approach on Broiler Industry in Jordan. Journal of Agricultural Science, v. 8, n. 12, p. 164, 2016.

AVILA, M. L.; AVILA, S. A.; FERREIRA, C. J. Administração rural: elementos de estudo na fazenda Córrego da Liberdade no município de Ipiranga de Goiás. Revista Eletrônica de Ciência Administrativa, v. 1, n. 2, p. 1-8, 2003.

BATALHA, Mário Otávio; BUAINAIN, Antônio Márcio; SOUZA FILHO, HM de. Tecnologia de gestão e agricultura familiar. In SOUSA FILHO, H.; BATALHA, M. O. (Org.). Gestão Integrada da Propriedade Familiar. São Carlos: UFSCAR, 2005.

BASTOS, R. R. Contabilidade do Agronegócio: um estudo exploratório sobre os conhecimentos dos contabilistas do município de Quixadá na região do sertão central do estado do Ceará. Revista Razão Contábil \& Finanças, Fortaleza, v. 2, n. 2, p. 1-18, 2011.

BREITENBACH, R. Gestão rural no contexto do agronegócio: desafios e limitações. 2014. Desafio Online, Campo Grande, v. 1, n. 2, art. 8, mai./ago. 2014.

BORILLI, S. P.; PHILIPPSEN, R. B.; RIBEIRO, R. G.; HOFER, E. O uso da Contabilidade Rural como uma ferramenta gerencial: um estudo de caso dos produtores rurais no município de Toledo - PR. Revista Ciências Empresariais da UNIPAR, Toledo, v. 6, n. 1, p. 77-95, 2005.

CLEMENTE, A.; SOUZA; A.; TAFFAREL, M.; GERIGK, W. Perfil das propriedades rurais familiares e controle de custos na região centro-sul do Paraná. Custos e @gronegócioonline, v. 6, n. 3, p. 21-43, 2010.

COSTA, C. C. M.; OLIVEIRA, L. G.; LIMA, L. B.; LIIRIO, V. S. A aplicação do método FMEA e suas implicações no planejamento de uma microempresa rural: estudo de caso da granja Oliveira. Revista Produção Online, v. 11, n. 3, p. 757-778, 2011.

CREPALDI, S. A. Contabilidade Rural: uma abordagem decisorial. 6. ed. São Paulo: Atlas, 2011.

CREVELIN, S. A.; SCALCO, A. R. Processo de implantação do projeto Agricultura Familiar Gado de Leite: Avaliação das práticas gerenciais. Informações Econômicas, v. 39, n. 11, p. 14-26, 2009. 
DOĞAN, Z.; ARSLAN, S.; KÖKSAL, A. G. Historical development of agricultural accounting and difficulties encountered in the implementation of agricultural accounting. International Journal of Food and Agricultural Economics, v. 1, n. 2, p. 107-115, 2013.

DORR, A. C.; GUSE, J. C.; FREITAS, L. A. R.; ROSSATO, M. V. Utilização de instrumentos de gestão contábil pelos produtores agropecuários. Revista Eletrônica de Contabilidade, v. 6, n. 1, p. 35-45, 2012.

DUDAFA, U. J. Record Keeping Among Small Farmers in Nigeria: Problems and Prospects. International Journal of Scientific Research in Education, v. 6, n. 2, p. 214-220, 2013.

TONEA, E. Does the accounting information influence the farm prosperity? Research Journal of Agricultural Science, v. 40, n. 3, p. 355-358, 2008.

FLORES, A. W.; RIES, L. R.; ANTUNES, L. M. Gestão Rural. Porto Alegre: Editora dos Autores. 2006.

GIL, A. C. Como Elaborar Projetos de Pesquisa. 5. ed. São Paulo: Atlas, 2010.

GUILHOTO, J. J. M; SILVEIRA, F. G.; ICHIHARA, S. M.; AZZONI, C. R. A importância do agronegócio familiar no Brasil. Revista de economia e sociologia rural, v. 44, n. 3, p. 355-382, 2006.

IBGE - INSTITUTO BRASILEIRO DE GEOGRAFIA E ESTATÍSTICA. Infográficos: despesas e receitas orçamentárias e PIB. 2014. Disponivel em: <http://cidades.ibge.gov.br/painel/economia.php?lang=\&codmun=430645\&search=rio-grande-do-sul|dois-lajeados|infogr\%E1ficos:-despesas-e-receitas-or\%E7ament\%E1rias-e-pib>. Acesso em: 21 abr. 2016.

KRUGER, S. D.; GLUSTAK, E.; MAZZIONI, S.; ZANIN, A. A Contabilidade como Instrumento de Gestão dos Estabelecimento Rurais. Revista de Administração, Contabilidade e Sustentabilidade - REUNIR, v. 4, n. 2, p. 134, p. 153, 2014.

LUCCA, E. J.; SILVA, A. L. L. Análise e diagnóstico de uma unidade de produção agrícola familiar. Revista de Administração IMED, v. 2, n. 3, p. 172-184, 2012.

MARCONI, M. A.; LAKATOS, E. M. Fundamentos de metodologia científica. 7. ed. São Paulo: Atlas, 2010. MARION, J. C. Contabilidade Rural: contabilidade agrícola, contabilidade da pecuária, imposto de renda pessoa jurídica. 12. ed. São Paulo: Atlas, 2010.

MARION, J. C.; SEGATTI, S. Contabilidade da pecuária. 9. ed. São Paulo: Atlas, 2010.

MARTINS, F. M. A gestão eficiente e sustentável da propriedade rural familiar em Laguna (SC). Laguna: Ed. Universitária da UNISUL. 2004. 
MAZZIONI, S.; ZANIN, A.; KRUGER, S. D.; ROCHA, J. L. K. A importância dos controles gerencias para o agribusiness. Revista Catarinense da Ciência Contábil, Florianópolis, v. 6, p. 9-26, 2007.

MELO, P. H. F.; CUNHA, J. V. A.; BAHIA, N. C. F. O processo decisório em propriedades rurais: análise do uso das ferramentas de gestão pelos produtores de leite do triângulo mineiro. ABCustos, São Leopoldo: Associação Brasileira de Custos, v. 10, n. 3, p. 55-79, set./dez. 2015

MENDONÇA, K.F.C.; RIBEIRO, A.E.M.; GALIZONI, F.M. Sucessão na agricultura familiar: estudo de caso sobre o destino dos jovens do alto Jequitinhonha, MG. In: XVI ENCONTRO NACIONAL DE ESTUDOS POPULACIONAIS, Caxambu-MG. Anais ... Caxambu-MG, 2008.

OLIVEIRA, D. L.; OLIVEIRA, G. D. Contabilidade Rural: uma abordagem do agronegócio dentro da porteira de acordo com o CPC 29, com exercícios práticos. Curitiba: Juruá. 2014.

OLIVEIRA, D. L.; ROSSONI, E. P.; FELICIANO, S. Inserção da Temática "Informação" nas Publicações em Agronegócio: Análise no Período de 2005 a 2009. Revista em Agronegócio e Meio Ambiente, v. 4, n. 2, p. 247-266, 2010.

RICHARDSON, R. J. Pesquisa Social: métodos e técnicas. São Paulo: Atlas, 1985.

RODRIGUES, A. O.; BUSH, C. M.; GARCIA, E. R.; TODA, W. H. A nova Contabilidade Rural. São Paulo: IOB, 2011.

RURALNEWS. Sucessão rural: o futuro da propriedade em jogo. 2015. Disponivel em: <http://www.ruralnews.com.br/visualiza.php?id=243 > Acesso em: 25 fev. 2014.

SALGADO, J. M.; REIS, R. P.; FIALHO, E. T. Perfil técnico e gerencial da suinocultura do Vale do Piranga (Zona da Mata) de Minas Gerais. Organizações Rurais \& Agroindustriais, v. 5, n. 2, p. 124-135, 2003.

SALUME, J. A.; SILVA, E. C. G.; CHRISTO, B. F. Elementos de administração rural avaliados em pequenas propriedades rurais de Alegre-ES. Caderno Profissional de Administração, v. 5, n. 1, p. 76-93, 2015.

SEDLÁČEK, J. et al. The methods of valuation in agricultural accounting. Agricultural Economics-Czech, v. 56, p. 59-66, 2010.

SHARMA, R. S. Accounting for Agriculture. International Journal of Recent Research and Review, v. 2, p. 62-66, 2012.

SILVA, P. R. et al. Relação Inversa. Revista Cultivar, Pelotas, v. 65, n. 1, p. 14-16, 2007. 


\section{Gestão \\ Desenvolvimento}

SILVA, A. C. R. Metodologia da Pesquisa Aplicada à Contabilidade: Orientações de Estudos, Projetos, Artigos, Relatórios, Monografias, Dissertações, Teses. São Paulo: Atlas, 2003.

ULRICH, E. R. Contabilidade rural e perspectivas da gestão no agronegócio. Revista de Administração e Ciências Contábeis do IDEAU, v. 4, n. 9, p. 1-13, 2009.

UTEGI, M.; UTEGI, E. N. The importance of farm records and accounting in agricultural production. Katsina-Ala Multidisciplinary Journal, 2014.

VAZAKIDIS, A.; STERGIOS, A.; LASKARIDOU, E. The importance of information through accounting practice in agricultural sector-European data network. Journal of Social Sciences, v. 6, p. 221-228, 2010.

VERGARA, S. C. Relatório de Pesquisa em Administração. 8 ed. - São Paulo: Atlas, 2007.

ZANIN, A.; OENNING, V.; TRES, N.; KRUGER, S. D.; GUBIANI, C. A. Gestão das propriedades rurais do Oeste de Santa Catarina: as fragilidades da estrutura organizacional e a necessidade do uso de controles contábeis. Revista Catarinense da Ciência Contábil, v. 13, n. 40, p. 9-19, 2014. 
APÊNDICE A - Questionário sobre Contabilidade em Propriedades Rurais

Este questionário objetiva o levantamento de dados para analisar o uso da contabilidade para controle e gestão da propriedade rural devendo ser respondido por produtores rurais. As perguntas foram adaptadas dos estudos na área, de Kruger et al. (2014) e Salume, Silva e Christo (2015). As informações obtidas serão tratadas de forma conjunta e a identidade dos respondentes será mantida em confidencialidade.

Parte I - Perfil Socioeconômico

1 - Qual é a sua idade?

( ) até 20 anos

( ) 21 a 30 anos

() 31 a 40 anos

( ) 41 a 50 anos

( ) 51 a 60 anos

( ) acima de 61 anos

2 - Qual é o seu nível de escolaridade?

( ) Ensino Fundamental Incompleto

( ) Ensino Fundamental Completo

( ) Ensino Médio Incompleto

( ) Ensino Médio Completo

( )Ensino Superior Incompleto

( ) Ensino Superior Completo

Se possui Ensino Superior citar em qual curso:

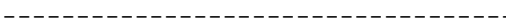

3 - Qual é a renda mensal média de sua propriedade?

( ) até $\mathrm{R} \$ 2.500,00$

( ) $R \$ 2.501,00$ a $R \$ 5.000,00$

( ) $R \$ 5.001,00$ a $R \$ 10.000,00$

( ) acima de $\mathrm{R} \$ 10.000,00$

4 - Quantos hectares tem sua propriedade?

\section{5 - Quantos hectares são cultivados?} 6 - Qual(is) a(s) principal(is) atividade/culturas desenvolvida(as) em sua propriedade?

( ) Milho

( ) Soja

( ) Fumo

( ) Trigo

( ) Uva

( ) Citros

( ) Morango

( ) Brócolis

( ) Louro

( ) Bovinos de Leite

( ) Suínos
( ) Aves

Outras - Descrever abaixo em caso de cultivo de outras

culturas/atividades não citadas acima.

7 - Na propriedade moram pessoas aposentadas ou que tem outra atividade?

( ) Não

( ) Sim, aposentado

( ) Sim, outras atividades

Se sim, quantas pessoas?

Qual a atividade?

8 - Você tem algum cargo de gestão/administração em sua comunidade?

( ) Sim

( ) Não

Se sua resposta for sim, descreva qual é o cargo:

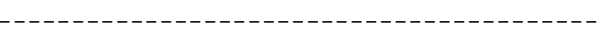

9 - A mão de obra (serviço) empregada na propriedade é:

( ) Totalmente familiar

( ) Parte familiar e parte terceirizada

( ) Totalmente terceirizada

( ) Outro - Descrever abaixo

10 - Quantos filhos você tem?

( ) Nenhum

( ) Tenho 1 filho

( ) Tenho 2 filhos

( ) Tenho 3 filhos

( ) Tenho mais de 3 filhos

11. Se você tem filho(s), quantos atuam na sua propriedade?

Parte 2 - Conhecimento e utilização de ferramentas contábeis

12 - Quem administra/gerencia a propriedade?

( ) eu e minha família

( ) tenho auxilio especializado.

Se for auxílio especializado, de quem?

13 - Você acha que seu conhecimento sobre gestão e

contabilidade, para controlar sua propriedade é:
( ) Totalmente satisfatório
( ) Parcialmente satisfatório
( ) Neutro
( ) Parcialmente insatisfatório
( ) Totalmente insatisfatório 
14 - Você separa seus gastos particulares, como comida, roupas, produtos de limpeza dos gastos da propriedade (ração animais, adubos, sementes)?

( ) Sim

( ) Não

15-Como são os controles da propriedade?

( ) não faço

( ) sei tudo de cabeça

( ) tenho tudo anotado em um caderno

( ) uso planilhas no computador

( ) tenho um sistema (programa) que controla tudo

16 - Você sabe qual é o lucro da propriedade, controlando quanto entra e quanto sai de dinheiro?

( ) Sim

( ) Não

17 - Você faz controle do valor das perdas, como por exemplo morte ou doença de animais, ou perdas de plantações por pestes ou tempestades?

( ) Sim

( ) Não

18 - Você planeja quanto precisa produzir para chegar a determinado lucro?

( ) Sim

( ) Não

19 - Você reinveste seu lucro na propriedade, comprando máquinas ou melhorando o processo produtivo?

( ) Sim

( ) Não

20 - Já participou de treinamento sobre gestão, controle e administração de propriedade rural?

( ) Sim

( ) Não

Se sim, onde fez o treinamento:

( ) Prefeitura

( ) Emater

( ) Sindicato

( ) Cooperativa

( ) Outros, qual:

21 - Como você considera o controle de sua propriedade:

( ) Totalmente insatisfatório

( ) Parcialmente insatisfatório

( ) Neutro

( ) Parcialmente satisfatório

( ) Totalmente satisfatório
E se o controle for satisfatório:

( ) não sei dizer quanto sobra por mês

( ) me dá uma ideia de quanto sobra

( ) sei quanto sobra na propriedade, mas não por atividade

( ) sei exatamente quanto sobra na propriedade em cada atividade

22 - Acredita que a contabilidade pode ajudar no controle de entrada e saída de valores, calcular o lucro e despesas da propriedade?

( ) Sim

( ) Não

23 - Se conhecesse melhor como funciona a contabilidade, a usaria para auxiliar na gestão de sua atividade?

( ) Sim

( ) Não

Agradeço sua disponibilidade por responder este questionário. 